\title{
¿LOS MISMOS PERROS CON DISTINTOS COLLARES? SOLUCIÓN DE CONTINUIDAD ENTRE LA TERCERA FUERZA Y LA TECNOCRACIA ESPAÑOLA
}

\author{
Jesús M. Zaratiegui \\ Universidad de Navarra \\ zlmosjsi@gmail.com \\ Alberto García Velasco \\ IES Santa Cristina de Lena, Asturias \\ albertogvelasco@gmail.com
}

RESUMEN: La política cultural, económica y social del franquismo vino marcada por las características ideológicas del grupo que en cada momento controlaba la agenda del régimen. En un primer periodo (1939-57) esta pugna se establece entre falangistas y el grupo del CSIC/Arbor. En el segundo (1957-75) contenderán para tomar las riendas el grupo falangista y los tecnócratas. Es fácil postular la continuidad de ideas, aunque con personas distintas. Entre los falangistas la realización de su revolución pendiente será la guía de acción. Más problemática es la continuidad del $2^{\circ}$ grupo. Es posible identificar vínculos entre los tradicionalistas y la institución religiosa Opus Dei. Pero subsiste la duda sobre la existencia de una estrategia tradicionalista/Opus Dei de control del Estado que se crearía como una plataforma cultural, para más tarde convertirse en proyecto político/económico.

Palabras clave: Tercera Fuerza, tecnocracia, Opus Dei, Falange, desarrollismo, Franco.

\section{THE SAME DOGS, DIFFERENT NECKLACES? SOLUTION OF CONTINUITY BETWEEN THE THIRD FORCE AND THE SPANISH TECHNOCRACY}

ABSTRACT: The economic and social cultural policy of Franquism was the outcome of the ideological fea-tures of the group that controlled the agenda of the regimen. In the first period (1939-57) the falangist and the traditionalist 
group cohesioned by the CSIC/Arbor. In the second period (1957-75) both groups would contend for control. It's not difficult to see the continuity of ideas. The falangists would try to put into practice their "unfinished revolution". But this continuity is least apparent when we come to the traditionalist group. It is possible to identify links between traditionalists and the religious institution Opus Dei. However, it is arguable whether exists or not a traditionalist/Opus Dei strategy of control of Government, through a cultural platform in the first period, that would turn into a political and economic project.

Keywords: Third Force, technocracy, Opus Dei, Falange, Franco.

Recibido: 11 de febrero de 2019

Aceptado: 14 de junio de 2019

\section{Introducción}

La Guerra de la Independencia sería el mito primigenio de donde arranca el ser de la comunidad política española que irá configurándose como nación a lo largo del siglo XIX ${ }^{1}$. La tesis de José Álvarez Junco resulta análoga a la que postula Santos Juliá ${ }^{2}$ y de ambas se desprende que la flexibilidad del lenguaje liberal le permitió erigirse en el gran protagonista de las tareas de reconstrucción en la etapa post-absolutista. Esta visión liberal heredera de los valores que alumbrara la Revolución Francesa, pero también de una interpretación historicista de las instituciones medievales españolas como precedentes del constitucionalismo ${ }^{3}$, va a convivir con una idea de España de corte más tradicionalista ${ }^{4}$. Hay que señalar, empero, que los primeros ilustrados y liberales españoles eran católicos casi sin excepciones. Pero el patriotismo conservador era básicamente tradicionalista porque seguía aferrado a la defensa del trono y del altar y recelará del potencial democrático del liberalismo. Este patriotismo consideraba que la esencia de nuestro país residía en la iglesia, la monarquía o el ejército, en las instituciones históricas, que orgánicamente habían construido España. Estas ideas de una constitución histórica interna eran asimismo defendidas por

1. Álvarez Junco, J., Mater dolorosa: la idea de España en el siglo XIX. Madrid 2001, pp. 15-35. Nombre éste (Guerra de la Independencia) que tardó 4 lustros en ser acuñado, lo que viene a confirmar el notable retraso con el que nuestros intelectuales acometieron la tarea de "hacer españoles".

2. Juliá, S., Historias de las dos Españas. Madrid 2004.

3. Nieto Soria, J. M., Medievo constitucional. Madrid 2007.

4. Fox, I., La invención de España. Nacionalismo liberal e identidad nacional. Madrid 1997. Riquer, B., Identitats contemporànies: Catalunya i Espanya. Vic 2000. Archilés, F. y M. Martí, "Un país tan extraño como cualquier otro: La construcción de la identidad nacional española contemporánea", en M. C. Romeo e I. Saz (eds.), El siglo XX. Historiografía e historia. Valencia 2002, pp. 245-278. 
liberales conservadores como Jovellanos o el británico Burke y no eran patrimonio exclusivo del tradicionalismo. Por tanto, desde el principio se advierte una contigüidad entre el tradicionalismo y el conservadurismo liberal lo que impide en este periodo establecer diferencias tajantes entre ambas doctrinas. El legitimismo dinástico, el carlismo, era la rama popular de este patriotismo católico, cuyas primeras formulaciones se podrían remontar a la guerra de la convención y al conocido libro de fray Diego José de Cádiz "El soldado católico en guerra de religión" (1794). En términos generales, en estas primeras décadas del siglo XIX el liberalismo era débil, debido al escaso desarrollo económico y urbano de la sociedad española y a su escaso grado de secularización. Este liberalismo de matriz doceañista pronto se dividirá en diversas tendencias al igual que otros liberalismos coetáneos. Finalmente, será el liberalismo conservador o moderantismo, paralelo al doctrinarismo francés, el constructor del Estado liberal español. El moderantismo español incluía, como antes sugeríamos, elementos doctrinales de corte tradicionalista, no en vano Donoso Cortés sería miembro destacado del ala derecha del Partido Moderado. Balmes también sería simpatizante de la misma formación política ${ }^{5}$.

Naturalmente, el liberalismo se dotó de un discurso sobre el esplendor, caída y renacimiento de España. La invención de la tradición liberal cobra fuerza con la Historia General de España de Modesto Lafuente (1850-1867), el primer intento de fijación de una "memoria colectiva" común como parte esencial de esa nueva cultura política que debían compartir los españoles de la era isabelina. Lafuente y sus epígonos de la historiografía liberal del siglo XIX comparten la idea de que la identidad española de los antiguos moradores de la península era indudable. La historia española presentaba caracteres inalterables que definirían España desde sus orígenes. Así pues, tradicionalismo y liberalismo moderado compartían un patriotismo que hacía del catolicismo y las instituciones tradicionales la piedra de toque de la identidad histórica española.

La historia española se atendría a los tres estadios clásicos de paraíso, caída y redención. Se trata de una secularización de las viejas historias de Alfonso X, Ximénez de Rada o el padre Mariana. La caída más significativa habría sido la invasión musulmana, auspiciada por la atávica división de los moradores de Hispania. La posterior Reconquista, culminada por los Reyes Católicos, creadores de la unidad política y religiosa española, es la redención por antonomasia, aquella en la que se mirarán una y otra vez tanto tradicionalistas como no tradicionalistas. Y es que tradición y modernidad no son dos elementos antitéticos o excluyentes. Más que de modernidad, término ambiguo y complejo, es más preciso hablar de modernización en un sentido económico, social y cultural. En este sentido, destacados tradicionalistas y conservadores serían profundamen-

5. Díez Del Corral, L., El liberalismo doctrinario. Madrid 1984. 
te modernizadores: desde Bravo Murillo hasta Gonzalo Fernández de la Mora pasando por Menéndez y Pelayo. En todo caso, no se puede establecer una dicotomía binaria entre tradición y modernidad:

What is modern or modernist gains its meaning through negation, as a rebellion against what once was or was presumed to be. Just as adjectives such as tall or big have meaning only in reference to other adjectives like short or small, the relational meaning for modern (and its siblings) exists within a comparative binary in which the opposite is traditional. Neither term has a fixed or universal meaning in and of itself, but rather acquires meaning only in relation to its implied opposite. Where tradition signals the unfolding of the future within the continuous pathways of the past, modernity calls for perpetual subversion of the past as the precondition of the future (...) The more modernity protests its absolute newness, the more it suppresses its rootedness in history. And the more that history is repressed, the more it returns in symbolic forms to haunt and disrupt the illusionary and ideological mythology of the new 6 .

Desde las postrimerías del siglo XIX nos encontramos con intelectuales que entienden su tarea como un activismo político y social (Maeztu) o que más allá de su condición de literatos se muestran contrarios a involucrarse en la vida política (Baroja). Intelectuales apasionados por el protagonismo popular (Araquistáin) o bien que se reconocen como superiores a la masa a la cual tratan de dirigir (Ortega). Intelectuales franquistas que suprimen del pasado español la herencia liberal y republicana (excluyentes) o que apuestan por la integración de lo salvable de dicha herencia en la España católica y falangista (comprensivos) ${ }^{7}$. Lo evidente es que la progresiva modernización social española decantó el protagonismo creciente de los intelectuales de una u otra tendencia ideológica dentro de los distintos conflictos políticos.

La restauración canovista tras el fallido intento democratizador del sexenio supuso la absorción de la Unión Católica de Alejandro Pidal y Mon por el partido conservador canovista. Los unionistas eran en parte herederos de Donoso Cortés y los neocatólicos. Es sabido que Marcelino Menéndez y Pelayo fue en sus inicios políticamente partidario de Alejandro Pidal y más tarde senador conservador. Como anteriormente había sucedido con el moderantismo, sus sucesores canovistas también tenían una fuerte impronta de pensamiento tradicional y católico. Al margen de la Restauración estaban, por supuesto, los carlistas de la Comunión Tradicionalista. Pero el pensamiento tradicionalista español no es únicamente sinónimo de carlismo. Y lo

6. Stanford Friedman, S., "Definitial Excursions: The Meanings of Modern / Modernity / Modernism", en Modernism/modernity, 8/3 (2001), pp. 503-504.

7. Díez, L., "Santos Juliá, Historia de las dos España, Taurus, Madrid, 2004". Comunicación y Hombre 1 (2005), pp. 225-230. 
importante es que a medida que avanza el siglo $X X$ una buena parte de la derecha española admite planteamientos de tipo tradicionalista, renegando incluso del tibio liberalismo doctrinario. Precisamente, es este pensamiento tradicional católico, que hunde sus raíces en el primer Menéndez y Pelayo y el último Donoso Cortés el que se desplegará posteriormente a través de Ramiro de Maeztu y Acción Española, el grupo de "excluyentes" aglutinados en torno a la figura de Rafael Calvo Serer y la revista Arbor desembocando finalmente en el grupo tecnocrático simbolizado en la persona de Laureano López Rodó. El estudio de las continuidades y discontinuidades en este largo proceso, al menos en la etapa posterior a 1939, será el eje central de nuestra investigación. Aunque se ha juzgado que el carácter confesional de la derecha española impidió la "cristalización de un nacionalismo secular, que acogiera bajo su égida al conjunto de la población española" ${ }^{8}$, otros autores ven a lo que luego se conocería como nacionalcatolicismo como el nacionalismo de la derecha española, "la plataforma ideológica del bloque de poder a partir de 1917"9, e hilo conductor de la corriente ideológica que es el nacionalismo antiliberal español (la otra sería la falangista, más débil y tardía). Para Ismael $\mathrm{Saz}^{10}$ el nacionalcatolicismo, esmaltado de fascismo, será el sustrato doctrinal definidor de la dictadura franquista, verdadera edad de oro de la derecha antiliberal española. Desde luego, el liberalismo y la izquierda resultaron barridos por el franquismo, si bien autores como Elías Díaz postulan una silenciosa continuidad del pensamiento liberal durante los años del franquismo ${ }^{11}$. En la misma línea el orteguiano Julián Marías identifica esa "vegetación del páramo" con la pervivencia de la cultura liberal bajo el franquismo ${ }^{12}$. Por el contrario, para autores como Ruiz Carnicer la ruptura es radical a causa de la muerte, exilio o muerte civil de tantos liberales españoles ${ }^{13}$.

No en vano, la historia intelectual del primer franquismo hasta 1957 es la historia de las pugnas entre las dos plataformas ideológicas (la tradicionalista y la falangista), ambas integradas en la coalición victoriosa, y que tratarán de

8. González Cuevas, P., El pensamiento político de la derecha española. Madrid 2005, p. 31. Para un panorama general de las derechas españolas contemporáneas, es útil el libro de J. Tusell, F. Montero y J. M. Marín (eds.), Las derechas en la España contemporánea. Barcelona 1997.

9. Botti, A., Cielo y dinero. El nacionalcatolicismo en España. Madrid 1993, p. 145.

10. Saz, I., España contra España. Los nacionalismos franquistas. Madrid 2003.

11. Díaz, E., Pensamiento español en la era de Franco (1939-1975). Madrid 1983, pp. $30-31$.

12. Marías, J., "La vegetación del páramo", en Ser español. Ideas y creencias en el mundo hispánico. Barcelona 1987.

13. Ruiz Carnicer, M. Á., "La cultura del poder. Propaganda en la alta manera," en J. Gracia y M. Á. Ruiz Carnicer, La España de Franco (1939-1975). Cultura y vida cotidiana. Madrid 2001, p. 156. 
liderar el proyecto de la Nueva España ${ }^{14}$. Autores como Juliá y Ferrary, aunque no coinciden en la terminología que usan para designar a cada grupo, sí lo hacen al reconocer dos modos distintos de entender la cultura, el significado de la nación y la política ${ }^{15}$ que se insertan en un grupo más amplio que ha estudiado la naturaleza del franquismo y su evolución a través de sus 40 años de vida ${ }^{16}$. A partir de la crisis de 1956 y el debilitamiento definitivo del proyecto falangista, Calvo Serer mudará de piel desde su integrismo católico y antiliberal hacia un estadio intermedio (la llamada Tercera Fuerza, presentada como una vía alternativa y superadora), que constituye el humus doctrinal del modelo tecnocrático.

De acuerdo con lo indicado en líneas anteriores, comenzamos analizando la introducción en España del ideario tradicionalista. A continuación, se ofrece un cuadro general de las diferentes modalidades que adopta, en especial los antagónicos proyectos del sector falangista y del grupo CSIC-Arbor. También señalaremos las líneas de continuidad entre estos últimos y el grupo tecnocrático dominante a partir de 1957, tratando de adelantar una descripción de los dos grupos que, según algunos autores, convivieron en el seno del Opus Dei, aunque con tácticas de acción distintas. Finalmente, caracterizamos a la tecnocracia como una modernización selectiva e instrumental del ideario del conservadurismo autoritario español derivado del tradicionalismo y del liberalismo conservador más a la derecha.

\section{Restauración franquista del ideario tradicionalista católico}

Las raíces del conservadurismo autoritario español hay que rastrearlas a partir de fines del siglo XVIII y principios del XIX, como ya hemos sugerido. Sin embargo, la formulación doctrinal más elaborada del pensamiento tradicionalista español aparece con las obras de Donoso Cortés, Balmes y Menéndez y Pelayo. Donoso tuvo una primera etapa doctrinaria para derivar luego hacia una concepción contrarrevolucionaria de la dictadura decisionista. Balmes era más templado aceptando la simbiosis entre el catolicismo y sociedad burguesa en formación. El conservador Menéndez y Pelayo se integró sin problemas en el sistema de la restauración canovista. Tres pensadores muy distintos de la derecha tradicional, ninguno carlista, y cuya influencia ideológica se dejará sentir profundamente: mantenimiento del orden social burgués, catolicismo como moral privada y pública y soluciones autoritarias al menos como posibilidad.

14. Hispán, P., La política en el régimen de Franco entre 1957 y 1969. Proyectos, conflictos y luchas por el poder. Madrid 2006, pp. 58-90.

15. Ferrary, Á., El franquismo: Minorías políticas y conflictos ideológicos 1936-1956. Pamplona 1993, pp. 115-119. Juliá, S., Historias de las dos Españas. Madrid 2004, pp. 358-366.

16. Molinero, C. y P. Ysàs, El règim franquista. Feixisme, modernització $i$ consens. Vic 2003. Esteban Navarro, M. Á, "La categorización política del franquismo. Un análisis de las principales aportaciones historiográficas", C.I.H. Brocar 13 (1987), pp. 11-26. 
La crisis del 98 obligó a repensar el ser de España en clave regeneracionista. Si bien el regeneracionismo tiene un sesgo ideológico liberal, el mismo Joaquín Costa recomendaría el cirujano de hierro como enérgica terapia autoritaria para solucionar los males de España. Por lo que respecta al universo conservador, será con los gobiernos técnicos de la dictadura de Primo de Rivera, herederos de una parte de la corriente maurista, de origen no se olvide liberal, cuando estas tendencias autoritarias se asienten definitivamente. Como recogen los estudios de Alejandro Quiroga ${ }^{17}$, la figura de Maeztu será esencial en estas corrientes. De una primera etapa regeneracionista, Maeztu pasará a ser en los años 30 el pensador de la contrarrevolución a través de Acción Española. González CaIleja ${ }^{18}$ califica a la dictadura de Primo de Rivera de modernización autoritaria. Su temprano carácter tecnocrático será la materia prima social e intelectual del franquismo. La idea clave era combinar la modernización socioeconómica con el entramado político tradicional. Este regeneracionismo conservador y católico perfila sus rasgos ideológicos básicos a partir de 1923.

El periodo finisecular asistió al nacimiento de los intelectuales con tal nombre. Son los intelectuales del cambio de siglo los que fijarán el relato de la decadencia, muerte y renacimiento de la patria. Esos relatos de la decadencia de la patria fueron a constituir el núcleo de ciertas corrientes ideológicas y políticas de la Europa de la época. Es muy claro en el caso de Francia con el surgimiento del "nacionalismo de los nacionalistas" en sus diferentes versiones. Maurras y Acción Francesa contenía elementos que influirían en el conservadurismo autoritario español. Entre otros, la idea de la Anti-Francia, la identificación consustancial entre patria y catolicismo o el rechazo absoluto del liberalismo y de la democracia. Por su parte, el novelista Maurice Barrés se situaba también en esa línea antiliberal, aunque en un sentido republicano y populista que nada podía gustar a Maurras.

Los liberales y socialistas españoles apostarán en cambio por la República. La clase intelectual apoyó la "república de los profesores" que para algunos autores representaría la culminación política del esfuerzo de sincronía cultural con el resto de Europa que se había iniciado a comienzos del $X X^{19}$. El "camino ancho y limpio" que señalaba Ortega rápidamente se arruinó con la polarización política y social que caracterizó al periodo republicano. El empuje revolucionario materializado en octubre de 1934 tuvo como reacción la contrarrevolución de las fuerzas conservadoras ${ }^{20}$. Por otro lado, tampoco el

17. Quiroga, A., Los orígenes del nacionalcatolicismo. José Pemartín y la dictadura de Primo de Rivera. Granada 2006.

18. González Calleja, E., La España de Primo de Rivera. La modernización autoritaria. Madrid 2005.

19. Marichal, J., El secreto de España. Madrid 1995, p. 242.

20. González Cuevas, P., Maeztu. Biografía de un nacionalista español. Madrid 2003. Morodo, R., Los orígenes ideológicos del franquismo: Acción española. Madrid 1985. Villacañas, J.L., Ramiro de Maeztu y el ideal de la burguesía en España. Madrid 2000. 
liberalismo español afrontó los retos planteados por la fracasada modernización republicana de una manera coherente: el liberalismo de izquierda se posicionó con los republicanos; el liberalismo conservador y elitista simbolizado por Ortega y Gasset apostó por una victoria del franquismo como mal menor frente a la revolución ${ }^{21}$.

La victoria franquista en la guerra dejó el campo libre para poner en práctica el proyecto político y cultural tradicionalista. Este era el molde de pensamiento de Franco (que había prologado las obras completas del asesinado Víctor Pradera) y de la iglesia católica, aunque no tanto del minúsculo grupo original que había devenido poderosa Falange y que reclamaba para sí la dirección del nuevo Estado. La "revolución pendiente" de Falange presentaba unos referentes ideológicos en parte distintos a los del tradicionalismo católico. Pronto fue evidente que falangistas y tradicionalistas se disputarían el control ideológico del régimen.

El Movimiento Nacional fue ante todo un instrumento de Franco para impulsar su propio proyecto político, garantizando a su vez la cooptación del personal político del régimen y el reparto de la administración pública entre los integrantes del bando vencedor. Piedra angular de este proyecto eran los militares. Franco garantizó a la alta oficialidad la propiedad de fábricas, empresas y tierras; cosa distinta serán los militares de rango medio y bajo, mal pagados, aunque siempre leales. Los falangistas controlaban el aparato sindical y colocaron a su gente. Los tradicionalistas y católicos, que a veces compartían la doble pertenencia al ser también militares (muchos alféreces provisionales), optarán por el mundo de la empresa (los empresarios de Franco) y un grupo menor por el mundo académico. Todos eran de tendencia monárquica, excepto los falangistas entre los que dominaba un posibilismo presidencialista.

Con la derrota de las potencias del Eje en la Guerra Mundial el componente falangista del franquismo fue progresivamente menguando. A partir de 1942 se acelera el proceso de desfascistización del régimen. Los franco-falangistas nunca supusieron un riesgo para Franco conformándose con el control de una serie de parcelas dentro del Estado a la espera de la "revolución pendiente". En términos ideológicos, el mensaje fascista original de los falangistas fue convenientemente aguado por considerables dosis de conservadurismo tradicional mucho más del gusto de Franco. Los últimos teóricos del fascismo español, como Arrese o Muñoz Alonso, no estaban muy alejados del conservadurismo católico ${ }^{22}$. Por su parte, los falangistas liberales se fueron volviendo cada vez más liberales y menos falangistas. En definitiva, el Partido Único naufragaba

21. Gracia, J., La resistencia silenciosa. Fascismo y cultura en España. Barcelona 2004.

22. De Diego, Á., José Luis Arrese o la falange de Franco. Madrid 2001. González Cuevas, P., El pensamiento político de la derecha española. Madrid 2005, p. 199 y ss. 
dentro de un irreversible vacío ideológico asistiéndose al crepúsculo de un fascismo español marcado por la burocratización, la rutina y el sometimiento al poder personal de Franco.

Como a la población únicamente se le exigía un asentimiento pasivo era relativamente fácil para Franco sustentar su dictadura personal en una variopinta selección de componentes ideológicos autoritarios (catolicismo político, corporativismo, militarismo, fascismo), en donde la Falange ya no tenía demasiada importancia y veía desvanecerse progresivamente cualquier esperanza de plantear la reconquista del Estado franquista. El vacío ideológico español fue de alguna manera colmado por el nacionalcatolicismo ${ }^{23}$. Para Ismael Saz ${ }^{24}$, el nacionalcatolicismo es "consciente y explícitamente reaccionario y contrarrevolucionario, parte del supuesto de la consustancialidad de lo español y lo católico, hace de la eliminación de lo no católico -la anti-España- el núcleo de su proyecto nacionalizador, acepta la modernidad capitalista y postula la vuelta a los sistemas de valores e instituciones anteriores a la revolución liberal: Iglesia, Monarquía, corporaciones y regiones". El nacionalcatolicismo no nace con la Guerra Civil, pero alcanzará su máxima hegemonía política e ideológica durante el franquismo, siendo la firma del Concordato con la Santa Sede en 1953 la "ratificación oficial y jurídica de la ideología del nacionalcatolicismo" 25 .

\section{Las empresas culturales para una restauración tradicionalista}

En los tempranos días de Burgos se conformaron los grupos de acción cultural que liderarían el proyecto de renovación tradicionalista y que conviven sin serios conflictos hasta finales de los 50. En enero de 1938 Eugenio D'Ors, Pedro Muguruza y Agustín González de Amezúa crean en esa ciudad el Instituto de España, que venía a recoger la tarea desempeñada desde 1910 a 1936 por la Junta de Ampliación de Estudios. Pronto convertido en Consejo Superior de Investigaciones Científicas, su nueva orientación le fue encomendada al catedrático de Instituto José María Albareda, amigo del ministro de Educación Nacional Ibáñez Martín. En su seno nacería la revista Arbor, que pretendía recoger y servir de escaparate de la labor desarrollada por el Consejo. La revista fue iniciada por Fray Justo Pérez de Urbel pero pronto sería refundada por el inspirador de su línea editorial durante años, Rafael Calvo Serer, miembro como Albareda del Opus Dei. Se asociaron pronto al grupo Florentino Pérez Embid, Jorge Vigón y Gonzalo Fernández de la Mora, que más tarde fijará la teoría de la tecnocracia

23. González-Anleo, J., Catolicismo nacional. Madrid 1975. Álvarez Bolado, A., El experimento del nacionalcatolicismo. Madrid 1976. Botti, A., Cielo y dinero. El nacionalcatolicismo en España. Madrid 1993.

24. Saz, I., España contra España: los nacionalismos franquistas. Madrid 2003.

25. Díaz-Salazar, R., El factor católico en la política española. Del nacionalcatolicismo al laicismo. Madrid 2006, p. 27. 
en su famoso libro El crepúsculo de las ideologías (1965). Gran parte de sus integrantes acabarán en la denominada Tercera Fuerza.

Esta nueva derecha monárquica utilizará como instrumento ideológico Arbor y otros medios informativos y culturales que eran la "contrarréplica" de la cultura liberal anterior a 1936. Como señala Prades ${ }^{26}$, Arbor "reivindicaba la vía española a la modernidad" atacando la quiebra del ideal de comunidad cristiana propiciado por el triunfo del nacionalismo, la libertad religiosa y el liberalismo político. Su proyecto político pasaba por la instauración de la monarquía tradicional y una modernización selectiva compatible con su ideario antiliberal y confesional. Los intelectuales de Arbor eran nacional católicos, tradicionalistas, y reclamaban la vuelta a la tradición española, que entendían contraria a la ilustración y el liberalismo. En este sentido, y sin tener en cuenta las diferencias que luego destacaremos, Díaz-Salazar" considera que "la mentalidad de los ideólogos desarrollistas y tecnócratas del Opus Dei también estaba impregnada de nacionalcatolicismo". Por tanto, estos sectores culturales y/o políticos franquistas eran herederos directos del pensamiento contrarrevolucionario y tradicionalista, aceptando sin embargo una modernización selectiva del país, que creían compatible con su ideario antiliberal y confesional; por lo tanto, doctrinalmente eran indiscutiblemente reaccionarios, pero a la vez recogían ciertas influencias del despotismo ilustrado y de la "revolución desde arriba" maurista. En este último aspecto, se podría advertir en ellos un tenue entronque con el liberalismo conservador.

Un segundo grupo cultural se fue conformando en torno a los falangistas Pedro Laín Entralgo, Subsecretario de Prensa y Propaganda del Ministerio de la Gobernación, y Dionisio Ridruejo, que en noviembre de 1940 pusieron en marcha la revista Escorial con el propósito de "contribuir al establecimiento de una comunidad intelectual". La firma de Ramón Menéndez Pidal en el primer número avalaba una cierta tolerancia intelectual. En realidad, el proyecto de Escorial entraba dentro del esquema fascista de asimilar todos aquellos elementos culturales que pudieran ser útiles a la nueva España. Al proyecto se sumaron jóvenes falangistas como Tovar, Laín, Ruiz-Giménez y, más tarde, Fraga. Es un grupo que irá aglutinando a todos los desencantados con el franquismo, pero sin soltar amarras con el régimen.

Este grupo falangista tenía dos satélites en su órbita. Por un lado, el Instituto de Cultura Hispánica que desarrolló una febril actividad en el mundo hispanoamericano bajo el impulso de Alfredo Sánchez Bella: becas a estudiantes, promoción de lazos históricos en clave tradicionalista, etc. Como era preceptivo, puso en marcha una revista, los Cuadernos Hispanoamericanos, y se fueron asociando

26. Prades, S., "Escribir la historia para definir la nación. La historia de España en Arbor 1944-1956". Ayer 66 (2007), pp. 177-200.

27. Díaz Salazar, R., El factor católico, p. 21. 
gente como Blas Piñar o los hermanos Martín Artajo, que conectaban a este grupo con el mundo católico de Acción Católica y la BAC. El otro proyecto fue el Instituto de Estudios Políticos, concebido como cantera de elites políticas del régimen, bajo la atenta mirada de Falange y de su primer director Fernando María de Castiella, más tarde ministro de Asuntos Exteriores. Frente a la inclinación juanista del grupo Arbor, la deriva del IEP, sobre todo a partir del nombramiento de F. Javier Conde, fue hacia enfoques presidencialistas no monárquicos ${ }^{28}$. El giro heterodoxo que Conde dará a la revista a partir de 1950, en la línea de Ortega, la apartó de la herencia intelectual de la España católica, abriendo sus páginas a autores de tendencia marxista y de extrema derecha, en una curiosa mezcolanza ideológica. Será el apoyo principal de José Luís Arrese en su intento por dotar al régimen de sustancia falangista en el fracasado intento de 1956.

Pero no es solo el primer grupo de tradicionalistas el que entronca con Donoso y Menéndez Pelayo. Así, no puede ignorarse la relación entre el falangismo de Laín y el catolicismo español que Menéndez Pelayo define como factor identificador de la nacionalidad. Laín escribirá un texto fundamental sobre el polígrafo santanderino que es respondido con acritud por Pérez Embid. Lo mismo puede decirse de Tovar, cuya antología del autor santanderino será, por el mismo motivo, objeto de críticas duras por parte del grupo de "Arbor" ¿No se declaraba Onésimo Redondo heredero directo del intelectual católico español, haciéndolo nada menos que padre del nacionalismo revolucionario del siglo XX? El mismo Tovar publicó en 1938 en los Breviarios del Pensamiento Español una antología de Donoso Cortés. Del mismo modo, se realiza una interpretación schmittiana de Donoso aproximándolo al pensamiento jurídico fascista. Finalmente, los hombres del grupo de Escorial consideran que José Antonio debe insertarse en la genealogía iniciada por Donoso, Balmes y Vázquez de Mella, de acuerdo con la lectura de Legaz Lacambra y José Corts Grau, que escriben tanto en órganos del catolicismo más militante como en Escorial (como, por otro lado, hacen Calvo Serer y otros, escribiendo reflexiones sobre la modernidad española en esta revista).

Esta comunión de ideas entre los elementos intelectuales de la Nueva España era compatible con una diversidad en la acción, buscada a propósito desde arriba para neutralizar estas fuerzas antagónicas en función de las distintas sensibilidades presentes en la coalición franquista: tradicionalistas, falangistas, gentes de la Tercera, liberales tolerados, democristianos etc. Hasta 1953 fue práctica común que se soliciten mutuamente artículos, colaboraciones o recensiones para aquellas publicaciones y que compartan escenarios en los cursos de verano de Santander y San Sebastián. Es a partir de esa fecha cuando comienza a agriarse la relación, apareciendo las críticas.

28. Muñoz Soro, J. y N. Sesma Landrín, "Redes de poder. La facultad de Ciencias Políticas y Económicas en la construcción del régimen franquista". Historia Social 79 (2014), pp. 107-128. 
Con todo, no conviene perder de vista que las elites políticas e intelectuales de la posguerra compartían un mismo humus cultural, religioso y social. De entrada, eran franquistas y en su mayor parte habían hecho la guerra en el bando nacional. Eran católicos y estaban convencidos de que el Nuevo Estado era depositario de la herencia cristiana que estaba en el origen de la cultura occidental. España tenía un papel específico en Europa: aportar la sustancia cristiana que los países dominados por las ideas liberales o marxistas parecían olvidar. Cuando entre 1945 y 1956 Calvo Serer viaje por Europa su objetivo será descubrir en esas sociedades a su juicio cada vez más paganizadas los elementos sanos capaces de restaurar la vieja doctrina del tradicionalismo católico, único garante ante los peligros que representaban el comunismo, la masonería y el judaísmo. Con ese objetivo primario nació en 1948 la Biblioteca del Pensamiento Actual, donde se traducirán libros de filósofos, teólogos e intelectuales europeos conservadores.

Obviamente, hubo otros elementos que actuaron un poco más al margen. El más influyente de todos fue José Ortega y Gasset. Inspirador de ese gran empeño cultural que fue la Revista de Occidente (1923-36), Ortega vuelve a España a vivir la última etapa de su vida (1945-1955). En esos diez años aún pudo aglutinar en sus cursos de Madrid a un nutrido grupo de discípulos entre los que destacó Julián Marías. Como escribió Ridruejo en 1954 "nuestro siglo XX se llama Ortega y Gasset". Ortega acabó llegando a un precario modus vivendi con un régimen que sin embargo no transigía con su laicismo o con su pasado republicano. Muchos han visto en Ortega las raíces de la teoría tecnocrática, aunque pueden encontrarse puntos de enlace en Joaquín Costa y otros. En todo caso, la tecnocracia que acaba arraigando en España es de matriz francesa, como hemos argumentado en otros trabajos.

En las historias del franquismo suele prevalecer la adscripción de cada periodo a la familia política (falangista, católica, tecnocrática) dominante en cada momento. Nos parece inexacto porque en definitiva es la cercanía a Franco la que les otorga en cada momento mayor o menor peso. Se entiende mejor el periodo analizando la fractura fundamental entre falangistas y tradicionalistas. Los primeros representaban un ideario más secular y estatalista, derivado de su origen fascista. Esto explica la "falangistización" del ideario franquista por parte de un grupo en su origen minúsculo. El elemento católico representa fundamentalmente un tradicionalismo derivado de Renovación Española y Acción Española. La continuidad la aportan los subgrupos tradicionalistas, los integrantes de la ACN de P (Martín Artajo, Ruiz-Giménez) y los hombres del Opus Dei. Ciertamente, el lugar donde Franco se encontró más a gusto fue entre militares y católicos y no tanto cerca del falangismo, al que utilizó para sus intereses, apropiándose de sus hombres y de sus símbolos.

Como ya en su momento indicara Payne ${ }^{29}$, Madrid era en 1955 la ciudad que sufría el mayor vacío político de Europa. Como a la población únicamente se le

29. Payne, S., Falange. Historia del fascismo español. Madrid 1985, p. 241. 
exigía un asentimiento pasivo, era relativamente fácil para Franco sustentar su dictadura personal en una variopinta selección de componentes ideológicos autoritarios (catolicismo político, corporativismo, militarismo, fascismo), en donde la Falange ya no tenía demasiada importancia y veía desvanecerse progresivamente cualquier esperanza de plantear la reconquista del Estado franquista. El vacío ideológico español fue de alguna manera colmado por el nacionalcatolicismo. Sobre este proyecto teológico-político, nos parece muy aceptable por su claridad el perfil que traza Díaz-Salazar ${ }^{30}$. Para Salazar, el nacionalcatolicismo es un fundamentalismo político-religioso caracterizado por la identidad entre España y catolicismo, la oposición al liberalismo y el autoritarismo político. Este mismo autor distingue tres grupos ideológicos generadores del pensamiento nacionalcatólico: el tradicionalismo integrista del grupo Acción Española; el catolicismo político de la ACN de P y el Opus Dei (Calvo Serer, Fontán); y el sector más estrictamente católico de Falange. Sobre los dos primeros sectores gravitaba con fuerza la sombra de Ramiro de Maeztu. Los hombres de la ACN de $\mathrm{P}$ son muy importantes en los gobiernos franquistas entre 1945-1957; a partir de 1957, comienza el desembarco de los tecnócratas (término que fue acuñado por los falangistas) vinculados al Opus Dei.

\section{Crepúsculo de Falange y ascenso de los tecnócratas ¿Son los tecnócratas herederos del tradicionalismo católico?}

La convivencia de "comprensivos" (los mal Ilamados falangistas liberales) ${ }^{31}$ e "intransigentes" (tradicionalistas) se rompió tras la publicación por Laín de su España como problema, contestado por Calvo Serer en España sin problema. Los dos libros fueron publicados en 1949. La brecha entre ambos grupos afectaba a la esencia misma de lo que debería ser España. Para los primeros era necesario rescatar todo lo bueno que se hallase en los vencidos porque todos representaban y ofrecían una parte de la verdad global que era España. Para los tradicionalistas, en cambio, la contienda bélica habría resuelto el problema para siempre con la eliminación de la semilla liberal, anticatólica y extranjerizante: se trataba de mirar al porvenir, pero para restablecer aquella España unida en lo político y en lo religioso que habían construido los Reyes Católicos y Trento.

30. Díaz Salazar, R., El factor católico, p. 15 y ss.

31. Como apunta Saz, la obsesión por ver "liberalismo" o tradición liberal aparece cada vez que en algún momento de los años 40 o 50 aparece el nombre de Ortega o el de otros intelectuales alejados del nacionalcatolicismo. Evidentemente, muchos de los falangistas protagonistas de sucesivos episodios provenían en buena parte de esa cultura moderna, secular y nacionalista. Por eso pudieron aparecer como "liberales" cuando eran puramente totalitarios, o pudieron mostrarse después como "comprensivos", cuando no hacían sino reproducir el esquema fascista de integrar al vencido después de destruirlo. Saz, I., reseña de Historias de las dos Españas de S. Juliá. Revista Internacional de filosofía política 27/1 (2006), p. 213. 
La llegada al Ministerio de Educación de un "comprensivo" como Joaquín Ruiz-Giménez supuso el nombramiento de sus correligionarios Laín y Tovar como rectores de Madrid y Salamanca. Ello no hizo sino reforzar la cohesión defensiva del grupo Arbor en torno al CSIC ante las acometidas del nuevo ministro para desmantelar y poner en la órbita universitaria la labor que desarrollaba el Consejo. La tensión alcanzó su clímax cuando en octubre de 1953 Calvo Serer publicó un artículo en una revista francesa en el que abiertamente acusaba a Ruiz-Giménez y su grupo de estar traicionando los ideales de unidad y ortodoxia que habían inspirado la cruzada ${ }^{32}$. En él postula la tercera fuerza como alternativa al falangismo de izquierdas ${ }^{33}$. Franco y Carrero conocían el contenido del artículo, pero no le perdonaron que lo publicase en el extranjero.

Calvo Serer aboga en su artículo por una nueva era a través de la Tercera Fuerza ya presente en la revista Arbor, la sección de Filosofía del CSIC y otros medios como las revistas Ateneo y Razón y Fe y los diarios ABC e Informaciones. Los mentores intelectuales de esta redirección del tradicionalismo serán Menéndez Pelayo, Maeztu y Pradera. El concepto vendría prestado de la obra Othman Spann, uno de los teóricos de la tercera vía entre la democracia y la dictadura totalitaria. "El filósofo de la historia español [Calvo] adaptó esta teoría a la España de 1953: los falangistas de izquierdas de raíz totalitaria y los democratacristianos habían fracasado y deberían dar paso a una tercera vía" ${ }^{\prime 34}$. Su cese en la dirección de Arbor provocó la disolución del grupo. El Español lo presenta como hombre sin familia que no cumplía con sus deberes académicos. Calvo Serer se defiende de los ataques de Fernández-Cuesta y Elorriaga: él sólo ataca al entorno del ministro, no a Franco ni al Movimiento. En noviembre de 1953 Escrivá se entrevista con Franco para quejarse del trato a Calvo Serer: este encuentro corta la campaña. Calvo Serer se recluye voluntariamente en Londres durante los meses siguientes. En marzo del 54 hay un nuevo Consejo en Arbor con savia nueva de raíz falangista.

Este primer grupo que lidera Calvo Serer está más orientado a las empresas culturales (Arbor, diario Madrid, Atlántica, Biblioteca de Pensamiento Actual) y son refractarios a la ciencia pura del grupo de Albareda en el CSIC o al derecho administrativo de López Rodó. Junto al valenciano debemos nombrar a Pérez Embid (en la política como Director General de Patrimonio Artístico) y a Fontán, que acabaría pronto integrado en el proyecto del diario Madrid. También son relevantes los nombres de Pániker, Saumells, y García Hoz. Estas personas constituyen la Tercera Fuerza. Junto a ellas hay un segundo grupo en torno al pragmático Luis Valls, que incluiría a López Rodó y a los hombres que ambos

32. Calvo Serer, R., "La politique intérieure dans L’Espagne de Franco", Écrits de Paris 107 (1953), pp. 9-18.

33. Díaz, O., Rafael Calvo Serer y el Grupo Arbor. Valencia 2008, pp. 551-556.

34. Díaz, O., Rafael Calvo Serer, p. 555 nota. 
promocionan para su entrada en el gobierno de 1957: Navarro Rubio ${ }^{35}$ y Ullastres. Del ámbito bancario habría que incluir a Rafael Termes. Como se advierte en la relación de incluidos y excluidos hay abundantes nombres relacionados con la institución religiosa del Opus Dei. Elías Díaz ha llegado a hablar de dos grupos tácticos dentro de esta institución, con similar ideología pero caminos distintos: unos, fieles a la ideología tradicionalista católica; los otros, aunando una modernidad en las cuestiones técnicas y económicas, pero con un similar tradicionalismo religioso ${ }^{36}$. El Opus Dei siempre ha puntualizado que una cosa es la institución con fines espirituales y apostólicos y otra distinta la actuación de sus miembros que en uso de su libertad habrían promovido empresas políticas y culturales de las que sólo ellos serían los responsables. Se afirma que no hubo nunca consignas de ningún tipo. Aunque para actuar por libre se ha llegado a una sorprendente unanimidad de opiniones.

Así argumentan Solís, Sánchez Bella, Fraga o Le Monde, lo mismo que en sentido opuesto lo hicieron Calvo Serer o López Rodó. Palabra contra palabra, estará pensando el lector. La tarea no es sencilla, sin embargo, y va más allá del cotejo fácil de textos espigados acá y allá. Entre otras razones porque estamos hablando de un largo periodo de tiempo (simplificando, treinta años, desde 1940 a 1970), los hombres cambian (¿quién reconocería al liberal Calvo Serer de los 60 en el tradicionalista de los 40?) y también las instituciones (del Instituto Secular que era el Opus Dei en los 40 a la Prelatura Personal ya larvada y prefigurada en los textos del Vaticano II; o la vigorosa Falange de la revolución pendiente transformada en oficina de colocaciones en los 60). Pero nuestro interés se centra en los proyectos que pusieron en marcha los hombres del Opus Dei: el proyecto cultural del grupo de Calvo Serer y su revista Arbor (19481953); y el proyecto político iniciado a partir de 1957 y que con diversas alternativas cobra fuerza hasta culminar en el gobierno monocolor de 1969 cuyo representante más destacado es L. López Rodó. Si hablamos de continuidades, el periodo clave sería 1953-57, porque en esas fechas los hombres de Calvo Serer desaparecen casi por completo de la escena política y cultural y los nuevos actores (López Rodó, Ullastres, Navarro Rubio) presentan un perfil político que nunca tuvo la empresa de Arbor y el CSIC $i S o n$ los mismos perros con distintos collares? ¿Vienen a completar un programa inacabado?

En este caso concreto cabría apuntar a tres componentes esenciales del nacionalcatolicismo que se prolongan a través de prácticamente un siglo. El primero es la esencialidad católica de España, con la consiguiente exclusión del pensamiento secular. Esta es una línea que podría llevar desde el primer Menéndez y

35. Navarro Rubio procedía del cuerpo jurídico militar. Llegó a la política por la vía del sindicalismo agrario vertical

36. Díaz, E., Pensamiento español en la era de Franco (1939-1975). Madrid 1983, pp. 34-37. 
Pelayo (brindis del Retiro) hasta Rafael Calvo Serer. En segundo lugar, el relativo a la plena aceptación de la modernidad económica capitalista, en una línea que va desde moderados como Bravo Murillo hasta López Rodó o Fernández de la Mora, pero que también comparten Calvo Serer o Pérez Embid. Y por último el modelo de Estado. En el caso de Acción Española y sus sucesores era un modelo que comportaba el principio de la superioridad de la Administración sobre la política. Sobre estas tres notas identificadoras basamos nuestro análisis para identificar si existe o no una continuidad esencial entre el proyecto tradicionalista de Calvo Serer en Arbor, luego continuado con su Tercera Fuerza, y los tecnócratas que aparecen a partir de 1957 aglutinados en torno a L. López Rodó. Con la característica notable de que una parte de los dos grupos, si es que se les puede dar tal nombre, pertenecen a la organización religiosa Opus Dei.

Superioridad de la administración sobre la política y enfoque confesional: esa fue una de las raíces fundamentales de los enfrentamientos entre los falangistas y sus aliados en 1937, 1941 y 1957. Esta racionalización administrativa conservando o intentando conservar la cosmovisión tradicional y católica significó el triunfo final de los tecnócratas del Opus Dei. Ismael Saz ${ }^{37}$ insiste en la idea de la modernización sin secularización analizando algunas propuestas de Santos Juliá: en realidad, no hacía falta citar a la religión para hablar de racionalización administrativa. Bastaba con que la España liberal siguiese sin levantar la cabeza, la Iglesia mantuviese su cuasi monopolio y reafirmar todo esto en otros textos como por ejemplo la Ley de Principios Fundamentales del Movimiento.

Abordar la cuestión siguiendo estas evidentes continuidades permite poner en sordina algunas dificultades que con frecuencia se aducen para establecer un hilo conductor. La primera es la falta de un análisis concluyente sobre los cauces de entrada en España de la doctrina tecnocrática y sus canales de transmisión. Por ejemplo, el libro de Fernández de la Mora El crepúsculo de las ideologías (1965) es una elaboración teórica ex post que poco dice de lo que pasa en los 50 y $60^{38}$. Luego están las personas que lo representan ya que hay una solución de continuidad entre los hombres de Arbor y los tecnócratas: el grupo de Calvo Serer se disuelve tras su derrota en 1953 y evoluciona en varias direcciones, pero no en la tecnocrática. Calvo Serer y Pérez Embid se muestran refractarios a la línea de ciencia pura de un Albareda y al enfoque administrativista de López Rodó o económico de Ullastres. Aunque también cabe preguntarse por qué los hombres más significados en política del Opus Dei (López Rodó, Ullastres, Navarro Rubio) adoptan con admirable ajuste el modo de pensar y hacer tecnocrático. Es decir, pierde fuerza la tecnocracia como hilo conductor de las conti-

37. Saz, I., Historia de las dos Españas, pp. 213-214.

38. Se puede consultar al respecto las aportaciones de J. M. Zaratiegui en dos libros colectivos (2012 y 2015) sobre la penetración de la tecnocracia en España. 
nuidades, al igual que pasaría a un segundo plano la cuestión de las personas, siempre que se pueda probar una continuidad esencial en las doctrinas.

Paradójicamente, los dos proyectos quedaron tocados, tanto el nacional católico (Pérez Embid dejó la Dirección General que ocupaba) como el falangista (por el desgaste de Falange y la desunión en Educación). Ruiz-Giménez, aparente vencedor de la contienda, quedó marcado a los ojos de Franco. Dos años más tarde lo relevará de su puesto en la crisis de febrero de 1956. Calvo Serer perdió su vieja cercanía a Franco. El Vigón que entra en el gobierno del 1957 estaba ya desligado de los ideales de Arbor. El terremoto no dejó a nadie indemne y rodaron las cabezas de los principales grupos culturales. Laín y Tovar dejaron el rectorado; Sánchez Bella acabó de embajador en la R. Dominicana del dictador Trujillo; el director del Instituto de Estudios Políticos, F. J. Conde, fue extrañado a la embajada de Manila. Incluso el director del Instituto de Estudios árabes fue de embajador al Líbano.

En todos los órdenes parecía un fin de ciclo. El modelo económico autárquico estaba agotado y era obvio que la promesa de Franco de pan en cada hogar estaba lejos de cumplirse. El cambio ministerial de febrero de 1957 abrió una nueva etapa en la política económica de nuestro país. El Plan de Estabilización y Liberalización (1959) y los Planes de Desarrollo (1964-74) jalonarán una etapa en la que la economía española experimentó un fuerte crecimiento. Comenzaba así una etapa más aburrida de la historia de España, en la que el énfasis pasó de lo doctrinal y lo político a lo económico. En 1957-58, bienio pre-estabilizador, se acometió una reforma tributaria y otra de tipos de cambio; se implementaron diversas campañas para combatir la inflación; y se avanzó en los primeros intentos de liberalización interior y exterior, eliminando en parte el férreo control del comercio. Dos ministerios aparecen como protagonistas de este cambio de rumbo: Hacienda (M. Navarro Rubio) y Comercio (A. Ullastres). Alentados por los organismos económicos internacionales (FMI, Banco Mundial), que exigían la adopción de una política económica ortodoxa, las autoridades franquistas no tuvieron más remedio que sacrificar el trasnochado proteccionismo patrocinado por los sectores falangistas en el altar de la eficacia tecnócrata. Esto tuvo su coste en forma de pérdida de influencia del sector falangista, mientras Presidencia del Gobierno (Carrero) se hacía con las riendas del control político y económico.

Atrás parecían quedar los debates intelectuales y políticos sobre la retirada o no del "Reservado el derecho de admisión" a las tareas de la paz. Pero seguía siendo un asunto sin resolver el problema que planteaba a España la suerte de los "malos españoles". La evolución hacia posiciones democráticas de las cabezas activas en el periodo anterior (Ruiz-Giménez y Calvo Serer) precipitó los intentos de institucionalización del régimen, acelerado en 1956 con el encargo de Franco a Arrese de elaborar un manual de guía para el buen orden de una democracia orgánica. El mal Ilamado falangismo liberal apostando por integrar a vencedores y vencidos no gustaba nada a Franco, que optó por la opción menos 
arriesgada de Ilamar al antiguo Secretario General del Movimiento. El fracaso del tardío intento fascistizador de Arrese abrió las puertas a los tecnócratas. Pero, ¿qué tenían en común los hombres de Arbor con los ministros Navarro Rubio y Ullastres? Desde luego, para los falangistas en tránsito hacia posturas más abiertas, los vencedores en la crisis del 57, los tecnócratas, pertenecían al mismo grupo que los hombres de Arbor. Ello nos pone en la pista de que el rótulo tecnócrata no aludía tanto a aspectos técnicos como a su cercanía al Opus Dei.

Franco dio a conocer la composición de su décimo gabinete en febrero de 1957. Este gobierno, que en sus piezas centrales perdurará hasta 1965, tuvo una notable consistencia y continuidad. El relevo tenía un hondo calado que RuizGiménez apuntaba al embajador Alfredo Sánchez Bella ${ }^{39}$; y ayuda a poner en contexto el conflicto entre dos concepciones dispares de la actividad pública: la más política de estos dos últimos y la técnica (tecnocrática se le llamará) de varios de los nuevos ministros y altos cargos, que entroncaría con los postulados de la Tercera y de su nuevo ideólogo Gonzalo Fernández de la Mora. RuizGiménez coincide con duros del régimen como Girón en que los responsables de la crisis de 1957 fueron los monárquicos tradicionalistas, la Tercera Fuerza, cuyo logro principal habría sido la expulsión del gobierno de todo su equipo (Laín, Tovar, Sánchez Bella) y el ascenso de J. Vigón, activo colaborador del grupo Arbor, como ministro de Obras Públicas. El nuevo gabinete incorporó dos técnicos competentes que creían en la economía de mercado y aplicarían esta orientación técnica a su gestión. En apariencia, por adscripción política y sociológica, parecían ser continuadores de las empresas de Calvo Serer, pero sus actuaciones mostrarían lo inexacto de la suposición.

La llegada de Ullastres al gobierno de 1957 admite varios patrocinios. Para Varela, Franco buscaba un buen administrador: "Ios déficit presupuestarios no le gustaban"40. Ullastres lo atribuye a su "especialización en asuntos monetarios de devaluación y estabilización cuando la gente no sabía nada de eso"41. También parece que intervino Navarro Rubio a quien Arrese pidió nombres para el ministerio de Comercio ${ }^{42}$. Versión que precisa López Rodó: "Me preguntó Carrero: ¿conoces a un catedrático de Economía que se llama Alberto Ullastres? (...) El Caudillo piensa nombrarle Ministro de Comercio. Luego he sabido que Franco conocía personalmente a su padre, alto directivo del Banco Hipotecario" ${ }^{\prime 43}$. Respecto a Navarro Rubio, Franco estaba al tanto de sus planes

39. Archivo Universidad de Navarra, Sánchez Bella, 58/235. Ruiz-Giménez a Sánchez Bella, 5 de marzo de 1957. 464.

40. Varela, M. (ed.), El FMI, el Banco Mundial y la economía española. Madrid 1994, p.

41. Bardavío, J., Historia del franquismo, entrevista a Ullastres en Diario 16 (28/IV/85), p. 471.

42. Navarro Rubio, M., Mis memorias. Barcelona 1991, p. 70.

43. López Rodó, L., Memorias. Madrid 1990, p. 91. 
para poner orden en el sistema hacendístico español, tras pasar un año antes el examen de Carrero, que pidió "mi opinión [de Navarro] sobre los problemas de la Hacienda Pública (...) en marzo de 1956 le escribí una simple carta en la que figuraba un pequeño repertorio de ideas" ${ }^{\prime 4}$.

Ullastres repetía que no era un ideólogo sino un teórico de la economía. Se consideraba apolítico y "el apelativo [tecnócratas] vino de la imposibilidad de etiquetarnos políticamente". No pertenecían a las familias tradicionales del régimen. "Éramos servidores del Estado (...) Habíamos sido llamados porque los políticos no entendían de economía, que entonces era una ciencia prácticamente nueva en España, y entonces nos Ilamaron a los técnicos" ${ }^{\prime 4}$. La técnica era su gran fuerza pero también su debilidad ya que se debían por completo a Franco. En sentido estricto, eran los más franquistas por pura necesidad de cobijo ideológico y personal. Aunque Ullastres, antiguo Alférez Provisional, tuvo siempre una visión relativamente objetiva de lo que era un régimen que consideraba biodegradable. "Porque el franquismo no tenía detrás una filosofía sistemática. Nació de una emergencia e iba capeando los tiempos de una u otra manera aunque sobre el denominador común, eso sí, de autoritarismo. El sistema iba diluyéndose poco a poco, y así se demostró a la muerte de Franco". La competencia profesional de estos hombres marginó a Franco de la dirección diaria del gobierno pero, paradójicamente, salió fortalecida su posición al atribuirse todos los éxitos económicos de sus subordinados ${ }^{46}$. A diferencia de los falangistas, que tenían su propia clientela, ellos dependían exclusivamente del favor del General. Jamás pensaron en desafiarle. López Rodó, Ullastres o Navarro Rubio le ofrecían a Franco eficacia y alivio de sus preocupaciones gubernamentales. Estos, a su vez, privados del soporte de seguridad de una familia ideológica, eran rehenes de la voluntad del hombre que los había llevado a la cumbre a través del poderoso Carrero Blanco.

\section{5. ¿La tecnocracia como secularización de la derecha autoritaria?}

El uso del apelativo tecnócrata se fue consolidando en la década de los 60 al compás del crecimiento del poder de López Rodó a la sombra de Carrero. Por lo que se refiere al periodo 1957-62, los sonados choques entre Navarro y Ullastres (López Rodó estaba aún en un discreto segundo lugar) aparcaron el debate sobre si la pertenencia al Opus Dei devenía en la formación de un grupo de poder o de presión, lo que es obvio tras el nombramiento de López Rodó como Ministro Comisario del Plan de Desarrollo (1962). Las críticas en estos primeros años se referían más bien al tono técnico que ambos ministros se proponían

44. Navarro Rubio, M., Mis memorias, pp. 72-74.

45. Bardavío, J., 1985, pp. 471-472.

46. Preston, P., Franco. Barcelona 1994, p. 864. 
dar a su gestión y que chocaba con la mentalidad de los elementos falangistas que no entendían una actividad pública que no fuera política. Dos ideologías enfrentadas: ¿de nuevo los comprensivos falangistas en pugna con los duros tradicionalistas? Lo único constatable es que la Falange hizo de la tecnocracia y sus postulados el blanco de sus ataques porque así se enfrentaban a la línea política sustentada por Carrero y López Rodó.

El apelativo de "tecnócratas" pronto se cargó de sentido al convertirse en sinónimo de pertenencia al grupo Opus, surgido en torno a los miembros de esa institución religiosa que ocuparían altos cargos en los años sucesivos (principalmente, Navarro Rubio, Ullastres, López Rodó y López Bravo) y aparentes herederos de Acción Española y el grupo Arbor. La asimilación no explica algunas cosas, como por ejemplo los roces entre un técnico como Albareda, secretario general del CSIC entre 1939 y 1966, con el grupo de la Tercera Fuerza, en especial Calvo Serer, empeñado en una empresa cultural, mientras el primero primaba la investigación científica sobre la acción política. Nunca se entendieron y todos quedaron marginados en los cambios de gobierno en 1957.

Por tanto, los elementos de la Tercera Fuerza habían quedado marginados del debate político. Calvo Serer, semi-exiliado y en acelerada conversión hacia planteamientos democráticos, batallaba contra el gobierno de su correligionario López Rodó desde las páginas del diario Madrid. Pérez Embid, ausente de la palestra política, estaba dedicado a tareas secundarias de índole cultural a través del Ateneo. El hombre más templado del grupo de Arbor, Antonio Fontán, se quejaba de la identificación que se hacía entre la Tercera Fuerza y la actividad política del Instituto Secular:

Decir entonces, o ahora, que constituíamos un "partido" político unitario, o siquiera coherente, no sólo es contrario a la verdad de la historia, representaría una ofensa a la inteligencia de los que pudieran oír o leer semejante cosa $-\mathrm{y}$ a la de las personas que he mencionado, comprendido yo mismo. (Sería como si dijéramos que Fal Conde, Iturmendi, Giménez Fernández, Gil Robles, Sainz Rodríguez, Pabón, Martín Artajo, Ruiz Giménez, Satrústegui, los miembros del Opus Dei que antes he mencionado, e innumerables políticos más, formaban parte en tiempos de Franco de un mismo partido político, por el mero hecho de ser todos católicos de doctrina y de práctica $)^{47}$.

Habría que matizar el sentido de las palabras de Fontán sobre la pertenencia a la institución, y no solo porque esto siempre se entendió en sentido muy amplio incluyendo a afines o simpatizantes. Tampoco el ejemplo que exhibe parece muy brillante: católicos eran casi todos en la España de Franco y es simplista hablar de un partido político que los englobara. Pero es indudable

47. Fontán, A., La actuación temporal de los cristianos. Buenos Aires 1962. 
la complejidad de postular la simple continuidad entre los tradicionalistas del grupo Arbor y los tecnócratas. El punto clave está en discriminar si se usó tal apelativo para connotar sin más la pertenencia al Ilamado grupo Opus, encarnado en la figura de López Rodó, o había algo más. El propio don Laureano afirmó en cierta ocasión que había venido a completar el programa de Rafael Calvo Serer. Es evidente la continuidad ideológica de ambos personajes, al menos hasta mediados de los 60. Sin embargo, cuando López Rodó busque inspiración para sus planes de desarrollo lo hará en la burocrática Francia (heredera del absolutismo, del bonapartismo y del presidencialismo fuerte), y no en Arbor ¿Cómo engarzan, si es que lo hacen, la tradición española de tecnocracia y la nueva francesa? ¿A través de Acción Francesa? A los de Arbor nunca se les llamó tecnócratas, parece más bien que se diluyen cuando esa tendencia se hace prevalente (y en casos como Fontán es reactivo). Como ha demostrado Zaratieguii ${ }^{48}$ el uso del término tecnócrata es más bien tardío, siendo en los años 1970-72 cuando se produce el mayor número de apariciones en prensa y revistas.

La más importante teorización del pensamiento tecnocrático vino con el libro El crepúsculo de las ideologías (1965) de Gonzalo Fernández de la Mora que propone "modificar la climatología social hasta hacerla inhabitable para las ideologías", sustituyéndolas por ideas "racionales, adecuadas y concretas". La demagogia de los políticos de oficio debe ser sustituida por los planes de desarrollo elaborados por los técnicos. Toda esta teorización de Fernández de la Mora era una manera de justificar el régimen en la medida en que éste garantizaba el progreso económico y social de los españoles gracias a la existencia de un Estado "de obras y de razón". Parecería, entonces, que la construcción teórica de Fernández de la Mora sí superaría el marco nacional católico, al rechazar completamente el pesimismo, el integrismo religioso o la visión cíclica de la Historia, constituyendo un claro ejemplo de pensamiento moderno e ilustrado alejado de la teología política ${ }^{49}$.

Esta supuesta asepsia política de los tecnócratas era objeto de debate ya que el enfoque técnico de los asuntos políticos había sido objeto de duras críticas por parte del grupo tradicionalista. La vieja pugna entre falangistas y estos últimos se planteará ahora con renovada virulencia. Un hombre como Ruiz-Giménez no creía "en la sustitución de los ideólogos por los tecnócratas. Creo que la tecnocracia es también una ideología, y desgraciadamente una de las ideologías más

48. Zaratiegui, J. M., "Los orígenes de la tecnocracia en España (1940-1962)", en A. Cañellas, La política de los profesionales. Tecnocracia y pensamiento conservador en Europa y América. Pamplona 2012, pp. 20-42.

49. Villacañas, J. L., Ramiro de Maeztu y el ideal de la burguesía en España. Madrid 2000. González Cuevas, P., "Dos respuestas a la crisis del catolicismo tradicional español (19561972)". El Catoblepas 131 (2013), p. 9. Goñi, C., Teoría de la razón política. El pensamiento político de Gonzalo Fernández de la Mora. Madrid 2013. 
conservadoras" 50 , aunque asimismo reconocía que "hoy no se puede ejercer la labor política con un ideario; además hace falta una información muy concreta de la realidad y unas técnicas. Técnicas de dominio de la naturaleza, y técnicas de dominio de la sociedad, o de gobierno de los hombres". El enfoque tecnocrático fue objeto de duras críticas desde posturas ideológicas enfrentadas. El crepúsculo de las ideologías fue atacado acerbamente por los sectores integristas en las revistas Punta Europa y Verbo por su empirismo, positivismo y exaltación del individualismo liberal ${ }^{51}$. Para Vicente Marrero, por ejemplo, Fernández de la Mora era un "conservador empírico", positivista y despreocupado de los aspectos espirituales. Entre la izquierda, las tesis "desideologizadoras" de Fernández de la Mora tampoco convencían, siendo objeto de críticas debido a su autoritarismo subyacente por parte de Raúl Morodo y Miguel Boyer en la revista Cuadernos para el diálogo ${ }^{52}$. El autoritarismo político era inherente a la empresa tecnocrática: creemos que Fernández de la Mora ${ }^{53}$ hablaba por todos cuando defendía como modelo político una "oligarquía renovada por cooptación". Cuando Salvador Pániker ${ }^{54}$ preguntaba a López Rodó sobre el futuro de España tras Franco, la respuesta del tecnócrata por antonomasia fue "después de Franco hay las leyes fundamentales que él ha promulgado". Se efectuarían pocos cambios que "alteraran el statu quo político" porque, para don Laureano, el "país necesitaría quietud". Quietud y leyes fundamentales: Laureano López Rodó tenía todo un programa político post Franco sin la menor relación con la democracia liberal. Sin embargo, en 1990 López Rodó decía en sus memorias que él siempre había propugnado el pluralismo en los esquemas intelectuales y en las ideologías políticas, estimando todas las libertades. Esta tardía aceptación de la democracia por parte de López Rodó permitió a Tusell encuadrar al tecnócrata catalán dentro de la derecha conservadora no integrista. Quizá paradójicamente, el almirante Luis Carrero Blanco, protector de los tecnócratas, se mantenía fiel a una concepción claramente integrista de la política y la sociedad. ${ }^{55}$

Así pues, creemos, siguiendo a González Cuevas, que con los cambios sociales experimentados en España gracias a la modernización económica de los años 60 la derecha antiliberal española se bifurcó en dos direcciones: por un lado, persistía el integrismo nacionalcatólico defendido por Carrero Blanco; era el caso de la revista Punta Europa y de los intelectuales integristas que en ella participaban, entre los que destacaba el martillo de orteguianos Vicente Ma-

50. Vilar, S., Protagonistas de la España democrática. La oposición a la dictadura: 19391969. Barcelona 1968, p. 462.

51. González Cuevas, P., El pensamiento político, p. 222.

52. Muñoz Soro, J., Cuadernos para el diálogo (1963-1973). Una historia cultural del segundo franquismo. Madrid 2005, pp. 126 y ss.

53. Fernández de la Mora, G., Río Arriba. Memorias. Barcelona 1995.

54. Pániker, S., Conversaciones en Madrid. Barcelona 1969, pp. 329-330.

55. Tusell, J., Carrero. La eminencia gris del régimen de Franco. Madrid 1993. 
rrero ${ }^{56}$; en cambio, la revista Atlántida, dirigida por Florentino Pérez Embid, recusaba el nacionalcatolicismo. Sus colaboradores, entre ellos Fernández de la Mora, defendían la libertad religiosa como inherente al cristianismo, la economía social de mercado, la planificación indicativa o la apertura a Europa.

Todos eran autoritarios y procedentes del catolicismo tradicional, pero nacional católicos y tecnócratas acabaron por chocar a la hora de afrontar las consecuencias de la modernización. Para los tecnócratas era posible una rectificación autoritaria de la modernidad, aceptando no obstante algunas de sus características, empezando por el weberiano "desencanto del mundo", aunque muchos de ellos pertenecieran a una institución religiosa como el Opus Dei que buscaba "la santificación de la vida cotidiana"; en el caso de los fieles al esquema más tradicional no existía ninguna posible reconciliación con una modernidad que creían materialista, relativista y atea. Su universo de creencias fundamentalistas no podía transigir con el inmanentismo inherente a la modernidad capitalista.

Con el final del franquismo, tecnócratas como López Rodó o Silva Muñoz participaron en la fundación en 1976 de Alianza Popular, el nuevo partido de la derecha conservadora postfranquista acaudillado por Manuel Fraga y dispuesto a recoger los votos del Ilamado franquismo sociológico. En Alianza Popular también colaboraba un Fernández de la Mora nada amigo de la democracia liberal. Contrario a la Constitución de 1978 ("España no necesita constitución porque es un Estado perfectamente constituido"), Fernández de la Mora acabó por abandonar Alianza Popular y posteriormente toda actividad política para concentrarse en una intensa actividad intelectual a través de la revista Razón Española, que fundó y dirigió hasta su muerte en 2002. Al final, la derecha autoritaria se esfumó del panorama político español democrático. Los profundos cambios económicos y sociales a partir de los años 60 habían propiciado también una intensa modificación de las mentalidades que abrió camino a la derecha liberal y marcó el ocaso de todas las variedades de la derecha autoritaria. Un verdadero crepúsculo de las ideologías del conservadurismo antiliberal español, que ha ensayado no obstante algunos débiles esfuerzos de renovación doctrinal.

\section{Conclusiones}

En las luchas de poder durante el primer franquismo encontramos dos grupos que pretenderán liderar la política cultural del régimen. El proyecto falan-

56. Habría que matizar el "integrismo" de Marrero. Era un tradicionalista inequívoco, del poco conocido carlismo canario, y con la particularidad de haberse formado con Heidegger, lo que le llevó a ver en Ortega un valedor del nazismo (con evidente exageración, y eso por más que las entrevistas entre Ortega y José Antonio cuenten con testigos de primera mano; el propio José Antonio era fascista, pero no era nazi). 
gista, ardoroso en etapas iniciales con su revolución pendiente, acomodaticio ya en los años 50, desarticulado como grupo a partir de la crisis de 1956 y el intento de Arrese de dar sustancia al régimen franquista con savia falangista, se vuelve irrelevante tras la crisis ministerial de 1969 y salen del gabinete Solís y Fraga, los dos últimos grandes del grupo falangista. El proyecto alternativo es el tradicionalista integrando por hombres cercanos al Opus Dei. La crisis de 1953, con la salida de Calvo Serer de sus cargos políticos, marca un antes y un después en el devenir de este grupo que pretende liderar el programa político e ideológico del Nuevo Estado.

El problema es la continuidad de los dos proyectos. Entre los tradicionalistas encontramos dos subgrupos que actúan en paralelo, con cierto grado de solapamiento en personas y programas, aunque con discontinuidad en lo que se refiere a protagonistas. Así, en el gobierno del 57 no entrará ninguno de los hombres de la Tercera Fuerza, salvo Jorge Vigón que pronto olvidará el proyecto Arbor. Los nuevos (Ullastres, Navarro Rubio) no parecen tener una relación previa con la Tercera. Es más, ambos eran originariamente parte de la oposición al grupo Arbor: Ullastres había desarrollado su carrera académica dentro del Instituto de Estudios Políticos, bastión de Falange, y Navarro Rubio estuvo siempre ligado a la OSE, también controlada por falangistas.

Sin embargo, pensamos que tienen más peso las continuidades entre los grupos de Calvo Serer y de López Rodó. Don Laureano siempre dijo que venía a completar el inacabado proyecto de Calvo. Es en los años 60 cuando se produce la bifurcación de esta derecha autoritaria entre modernizadores autoritarios y tradicionalistas nacional católicos. Los tecnócratas herederos de la Tercera Fuerza serían los modernizadores autoritarios con Gonzalo Fernández de la Mora, su líder intelectual, a la cabeza. Y todo ello de acuerdo con el siguiente esquema:

1. La modernización selectiva del conservadurismo autoritario español supuso importantes cambios en su cosmovisión, aceptando que en una sociedad modernizada y de clases medias el nacionalcatolicismo acabaría siendo un componente anacrónico y marginal. Los tecnócratas eran católicos tradicionales, sin duda, pero admitían que tras el Concilio Vaticano II y los grandes cambios experimentados por la sociedad española ya no había lugar para integrismos. El integrismo no obstante sobrevivió en determinados círculos intelectuales cada vez más minoritarios como la revista tomista Verbo y políticamente en la ultraderechista Fuerza Nueva del notario Blas Piñar.

2. De esta forma, la retórica de la Cruzada como legitimadora del régimen fue sustituida por un lenguaje burocrático y árido donde se proponían como nuevos ideales la no ideología, el desarrollismo y una curiosa confianza en la apatía política del pueblo español. Para este positivismo autoritario (como lo denominó acertadamente en su momento el intelectual integrista Vicente Marrero) la mejor justificación del franquismo estaba 
¿LOS MISMOS PERROS CON DISTINTOS COLLARES? SOLUCIÓN DE CONTINUIDAD...

en la enumeración de sus logros económicos y en su capacidad para propiciar el progreso nacional. Salvando las distancias, era un discurso parecido al de un Bravo Murillo y otros autoritarios decimonónicos.

3. Esta derecha tecnocrática y aparentemente no ideológica conservaba no obstante bastantes reminiscencias de su origen en la derecha tradicional católica. En primer lugar, se trataba de una derecha no democrática y no liberal debido a su concepción orgánica/corporativa de la sociedad y de la representación política. Desde este punto de vista, España estaba ya perfectamente constituida con la democracia orgánica y su representación corporativa y restringida de los intereses de los distintos grupos sociales.

4. En este esquema modernizador pero autoritario no había lugar para los partidos políticos, los sindicatos libres o las agrupaciones patronales; tampoco se reconocía la soberanía nacional y el consecuente derecho al sufragio universal; además, desde una concepción elitista y orgánica de la sociedad, al ciudadano se le consideraba como menor de edad, apartándole por completo de las actividades políticas, que eran privilegio exclusivo de los profesionales y los técnicos.

5. La oposición al liberalismo político, no económico, el elitismo y el autoritarismo iban de la mano en este conservadurismo tecnocrático heredero de la Tercera Fuerza. Sin embargo, su estrategia de mantener el franquismo por otros medios tras la muerte de su titular se reveló como profundamente utópica. Una sociedad cada vez más diversificada y secularizada como era la española difícilmente podía ser mantenida en perpetuo estado de minoría de edad política con el señuelo de un desarrollo económico permanente.

\section{Bibliografía}

Álvarez Junco, J., Mater dolorosa: la idea de España en el siglo XIX. Madrid 2001. Álvarez Bolado, J., El experimento del nacionalcatolicismo. Madrid 1976.

Archilés, F. y M. Martí, "Un país tan extraño como cualquier otro: La construcción de la identidad nacional española contemporánea", en M. C. Romeo e I. Saz (eds.), El siglo XX. Historiografía e historia. Valencia 2002, pp. 245-278.

Bardavío, J., Historia del franquismo, entrevista a Ullastres. Diario 16 (28 abril 1985).

Botti, A., Cielo y dinero. El nacionalcatolicismo en España. Madrid 1993.

Calvo Serer, R., "La politique intérieure dans L'Espagne de Franco". Écrits de Paris 107, 9 (1953), pp. 9-18.

De Diego, Á., José Luis Arrese o la falange de Franco. Madrid 2001.

Díaz, E., Pensamiento español en la era de Franco (1939-1975). Madrid 1983. 
Díaz, O., Rafael Calvo Serer y el Grupo Arbor. Valencia 2008.

Díaz-Salazar, R., El factor católico en la política española. Del nacionalcatolicismo al laicismo. Madrid 2006.

Díez, L., "Santos Juliá, Historia de las dos Españas, Taurus, Madrid, 2004". Comunicación y Hombre 1 (2005), pp. 225-230. https://doi.org/10.32466/eufvcyh.2005.1.500.225-231.

Díez del Corral, L., El liberalismo doctrinario. Madrid 1984.

Esteban Navarro, M. Á., "La categorización política del franquismo. Un análisis de las principales aportaciones historiográficas". Cuadernos de Investigación Histórica. Brocar 13 (1987), pp. 11-26. http://doi.org/10.18172/ brocar. 1822 .

Fernández de la Mora, G., El crepúsculo de las ideologías. Barcelona 1971.

Fernández de la Mora, G., Río arriba. Memorias. Barcelona 1995.

Ferrary, Á., El franquismo: Minorías políticas y conflictos ideológicos 1936-1956. Pamplona 1993.

Fontán, A., La actuación temporal de los cristianos. Buenos Aires 1962.

Fox, I., La invención de España. Nacionalismo liberal e identidad nacional. Madrid 1997.

González-Anleo, J., Catolicismo nacional. Madrid 1975.

González Calleja, E., La España de Primo de Rivera. La modernización autoritaria. Madrid 2005.

González Cuevas, P., Maeztu. Biografía de un nacionalista español. Madrid 2003.

González Cuevas, P., El pensamiento político de la derecha española. Madrid 2005.

González Cuevas, P., "Dos respuestas a la crisis del catolicismo tradicional español (1956-1972)". El Catoblepas 131 (2013). http://www.nodulo.org/ ec/2013/n131p09.htm (consultado 7 octubre 2014).

Goñi, C., Teoría de la razón política. El pensamiento político de Gonzalo Fernández de la Mora. Madrid 2013.

Gracia, J., La resistencia silenciosa. Fascismo y cultura en España. Barcelona 2004.

Hispán, P., La política en el régimen de Franco entre 1957 y 1969. Proyectos, conflictos y luchas por el poder. Madrid 2006.

Juliá, S., Historias de las dos Españas. Madrid 2004.

López Rodó, L., Memorias. Madrid 1990.

Marichal, J., El secreto de España. Madrid 1995.

Marías, J., "La vegetación del páramo", en Ser español. Ideas y creencias en el mundo hispánico. Barcelona 1987. 
Molinero, C. y P. Ysàs, El règim franquista. Feixisme, modernització i consens. Vic 2003.

Morodo, R., Los orígenes ideológicos del franquismo: Acción española. Madrid 1985.

Muñoz Soro, J., Cuadernos para el diálogo (1963-1976). Una historia cultural del segundo franquismo. Madrid 2005.

Muñoz Soro, J. y N. Sesma Landrín, "Redes de poder. La Facultad de Ciencias Políticas y Económicas en la construcción del régimen franquista". Historia social 79 (2014), pp. 107-128.

Navarro Rubio, M., Mis memorias. Barcelona 1991.

Nieto Soria, J. M., Medievo constitucional. Madrid 2007.

Pániker, S., Conversaciones en Madrid. Barcelona 1969.

Payne, S., Falange. Historia del fascismo español. Madrid 1985.

Prades, S., "Escribir la Historia para definir la nación. La historia de España en Arbor 1944-1956". Ayer 66 (2007), pp. 177-200.

Preston, P., Franco. Barcelona 1994.

Quiroga, A., Los orígenes del Nacionalcatolicismo. José Pemartín y la Dictadura de Primo de Rivera. Granada 2006.

Riquer, B. de, Identitats contemporànies: Catalunya i Espanya. Vic 2000.

Romeo, M. C. e I. Saz, El siglo XX. Historiografía e historia. Valencia 2002.

Ruiz Carnicer, M. Á., "La cultura del poder. Propaganda en la alta manera," en J. Gracia y M. Á. Ruiz Carnicer, La España de Franco (1939-1975). Cultura y vida cotidiana. Madrid 2001.

Saz, I., España contra España: los nacionalismos franquistas. Madrid 2003.

Saz, I., Fascismo y franquismo. Valencia 2004.

Saz, I., "Santos Juliá, Historia de las dos Españas, Taurus, Madrid, 2004". Revista Internacional de Filosofía Política 27/1 (2006), pp. 211-214.

Stanford Friedman, S., "Definitial Excursions: The Meanings of Modern/Modernity/Modernism". Modernism/modernity 8/3 (2001), pp. 493-513.

Tusell, J., Carrero. La eminencia gris del régimen de Franco. Madrid 1993.

Tusell, J., F. Montero y J. M. Marín (eds.), Las derechas en la España contemporánea. Barcelona 1997.

Varela, M. (ed.), El FMI, el Banco Mundial y la economía española. Madrid 1994.

Vilar, S., Protagonistas de la España democrática. La oposición a la dictadura: 1939-1969. Barcelona 1968.

Villacañas, J. L., Ramiro de Maeztu y el ideal de la burguesía en España. Madrid 2000. 
Zaratiegui, J. M., "La tecnocracia en España (hasta 1939)", en Á. Ferrary y A. Cañellas, El régimen de Franco. Pamplona 2012, pp. 187-218.

Zaratiegui, J. M., "Los orígenes de la tecnocracia en España (1940-1962)", en A. Cañellas, La política de los profesionales. Tecnocracia y pensamiento conservador en Europa y América. Pamplona 2015, pp. 20-42. 